\title{
BMJ Open The efficacy of dapagliflozin combined with hypoglycaemic drugs in treating type 2 diabetes mellitus: meta-analysis of randomised controlled trials
}

\author{
Yu-nan Sun, ${ }^{1}$ Yi Zhou, ${ }^{1}$ Xi Chen, ${ }^{1}$ Weng-si Che, ${ }^{1}$ Siu-wai Leung ${ }^{1,2}$
}

To cite: Sun $Y$, Zhou $Y$, Chen $X$, et al. The efficacy of dapagliflozin combined with hypoglycaemic drugs in treating type 2 diabetes mellitus: meta-analysis of randomised controlled trials BMJ Open 2014;4:e004619. doi:10.1136/bmjopen-2013004619

- Prepublication history and additional material is available. To view please visit the journal (http://dx.doi.org/ 10.1136/bmjopen-2013004619).

YS and $Y Z$ are joint first authors.

Received 4 December 2013 Revised 14 March 2014 Accepted 17 March 2014

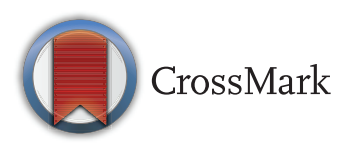

${ }^{1}$ State Key Laboratory of Quality Research in Chinese Medicine, Institute of Chinese Medical Sciences, University of Macau, Macao, China ${ }^{2}$ School of Informatics, University of Edinburgh, Edinburgh, Scotland, UK

Correspondence to Siu-wai Leung; siu@inf.ed.ac.uk

\section{ABSTRACT}

Objectives: This meta-analysis aimed to evaluate whether dapagliflozin is synergistic with other antidiabetic drugs without body weight gain.

Setting: Randomised controlled trial (RCT) reports were retrieved from PubMed, Cochrane Library, EMBASE, ClinicalTrials.gov, Google Scholar and Google. Eligible RCTs were selected according to the criteria (including types of participants, intervention, outcomes) and assessed by the Cochrane risk of bias tool and GRADEpro software for evidential quality. Meta-analysis on the eligible RCTs was performed with the random effects model. The RCTs of low-quality and interim stages were excluded for further sensitivity analysis. Meta-regression was conducted on the follow-up durations. Publication bias was evaluated with funnel plots and the Egger's regression test and adjusted using the trim-and-fill procedure. Heterogeneity was assessed with the $\mathrm{I}^{2}$ statistics. Participants: Adult patients with type 2 diabetes mellitus (T2DM).

Interventions: Dapagliflozin combined with conventional antidiabetic drugs.

Primary and secondary outcome measures: Glycaemic level (measured by glycosylated haemoglobin (HbA1c) and fasting plasma glucose (FPG)) and body weight.

Results: 12 RCTs were eligible for quantitative synthesis and meta-analysis. The overall effect size of $\mathrm{HbA1c}$ calculated from mean difference was $-0.52 \%$ $(Z=-13.56, p<0.001)$ with $95 \% \mathrm{Cl}(-0.60$ to -0.45$)$. The effect size of FPG was $-1.13 \mathrm{mmol} / \mathrm{L}(\mathrm{Z}=-11.12$, $p<0.001)$ with $95 \% \mathrm{Cl}(-1.33$ to -0.93$)$. The effect size of body weight was $-2.10 \mathrm{~kg}(Z=-18.77$, $p<0.001)$ with $95 \% \mathrm{Cl}(-2.32$ to -1.88$)$. Exclusions of low quality and interim RCTs changed the overall mean differences respectively to $-0.56 \%,-1.11 \mathrm{mmol} / \mathrm{L}$, $2.23 \mathrm{~kg}$ and $-0.50 \%,-1.08 \mathrm{mmol} / \mathrm{L},-2.08 \mathrm{~kg}$. The sensitivity analysis indicated good robustness of the meta-analysis on HbA1c, FPG and body weight. Conclusions: The meta-analysis showed that dapagliflozin as an add-on drug to conventional antidiabetic drugs improved the glycaemic control in T2DM participants without significant body weight gain.

Trial registration number: CRD42013005034.

\section{Strengths and limitations of this study}

- This study is the first meta-analysis to focus on the efficacy and body weight gain issue of dapagliflozin versus placebo in synergy with antidiabetic drugs (not only metformin).

- The protocol of this study was properly registered with the PROSPERO database and published.

- The conduct and reporting of this study is in accordance with the Preferred Reporting Items for Systematic Reviews and Meta-analyses (PRISMA) statement to ensure high study quality.

- Subgroup meta-analysis, sensitivity analysis and publication bias analysis were performed to evaluate the robustness of the evidence.

- A meta-regression was conducted to determine dapagliflozin had long-term ( $>24$ weeks) effects on controlling fasting plasma glucose and body weight of type 2 diabetes mellitus participants.

- There is a potential limitation of the study that all eligible RCTs were sponsored by Bristol-Myers Squibb or AstraZeneca.

\section{INTRODUCTION}

The efficacy of common antidiabetic drugs (including metformin, sulfonylureas, nonsulfonylurea secretagogues, $\alpha$-glycosidase inhibitors, thiazolidinediones, glucagon-like peptide-1 analog and dipeptidyl peptidase- 4 inhibitors) is insulin-dependent. ${ }^{1}$ Their efficacy diminishes when the function of pancreatic islet $\beta$-cells declines during the progression of type 2 diabetes mellitus $(\mathrm{T} 2 \mathrm{DM}) .^{2}$ Sulphonylureas and thiazolidinediones cause body weight gain, which further worsens insulin resistance. ${ }^{3}$ It came as no surprise that approximately two-thirds of the patients with diabetes in Europe $^{4}$ and the USA $^{5}$ under conventional treatment could not meet the goal of glycaemic control. By contrast, as a highly selective inhibitor of sodium glucose co-transporter 2 (SGLT2), 
dapagliflozin is distinctive in its insulin-independent action on reducing reabsorption of glucose particularly by the proximal tubule in the kidney to eliminate more glucose from plasma into urine.$^{6-8}$ Dapagliflozin would enhance glycaemic control, as claimed in recent studies, without adverse effects on body weight, blood pressure and lipids such as conventional antidiabetic drugs, making it desirable to combine conventional antidiabetic drugs with dapagliflozin in treating T2DM. ${ }^{9} 10$ However, these claims were made by individual clinical studies, not well-established by the systematic reviews and meta-analysis. Three existing meta-analysis reports did not focus on dapagliflozin but addressed the efficacy issues of SGLT2 inhibitors in general. ${ }^{3}{ }^{11} \quad 12$ The meta-analysis ${ }^{13}$ on dapagliflozin in particular still lacked an analysis of publication bias, that is available publications do not fully represent the researches that have been carried out, and sensitivity to various possible factors as required by the Preferred Reporting Items for Systematic Reviews and Meta-analyses (PRISMA) guideline for meta-analysis reporting. Although a subgroup analysis on dapagliflozin monotherapy was available in the meta-analysis, ${ }^{13}$ it did not provide specific analysis of the efficacy of dapagliflozin combined with other antidiabetic drugs. The latest meta-analysis used the Bayesian method to estimate the relative effect of dapagliflozin versus other antidiabetes treatments (not placebo) added to metformin therapy. ${ }^{14}$ All these five meta-analysis studies were not registered before conduct. The present meta-analysis aims to evaluate the synergistic efficacy of dapagliflozin versus placebo in combination with conventional antidiabetic drugs for glycaemic control as measured by the changes of glycosylated haemoglobin (HbAlc) and fasting plasma glucose (FPG). The body weight data were analysed to test the claim that dapagliflozin does not affect body weight (ie, no weight gain).

\section{METHODS}

This study of systematic review and meta-analysis is in compliance with the guideline PRISMA. The protocol of this study ${ }^{15}$ was registered with the PROSPERO database and assigned an identifier CRD42013005034.

\section{Data sources}

Bibliographical databases for literature search included MEDLINE (via PubMed), EMBASE (via OVID), Cochrane Library, Google Scholar and ClinicalTrials.gov (http://www.clinicaltrials.gov). The initial search was performed on 9 July 2013 and was last updated on 21 October 2013. Our search strategy included keywords 'dapagliflozin' and 'diabetes'. We searched all fields in PubMed, all text in Cochrane Library, but restricted to the fields of abstracts, titles and keywords in EMBASE. When searching ClinicalTrials.gov, we used the term 'dapagliflozin'. Google search was conducted to find the randomised controlled trial (RCT) information unavailable from bibliographical databases. In addition, manual search of journals was conducted to track relevant RCTs that were not indexed by normal keywords.

\section{Inclusion and exclusion criteria}

The identified studies were selected according to the following inclusion and exclusion criteria.

Study design: Only RCTs were included. Observational, cohort, case-control, case series and laboratory studies were excluded.

Durations: For observing changes in HbAlc levels, only the RCTs with follow-up durations longer than 8 weeks were included.

Participants: Only the RCTs on adult patients with T2DM (age $\geq 18$ ) were included.

Interventions: This meta-analysis included only the RCTs on the efficacy of dapagliflozin combined with conventional antidiabetic drugs. The RCTs on dapagliflozin monotherapy were excluded.

Comparators: This meta-analysis included the RCTs employing placebo combined with conventional antidiabetic drugs as the controls. The RCTs employing only placebo as the control group were excluded.

Outcomes: This meta-analysis included the RCTs measuring HbA1c, FPG and body weight as the outcomes. The RCTs without all these three outcomes were excluded.

\section{Study selection and data extraction}

The studies were evaluated by at least two reviewers according to the inclusion and exclusion criteria. Disagreement in evaluation was resolved by discussion among the reviewers.

Data from each included RCT were extracted by one reviewer and verified by another reviewer. In addition to the outcome measures, the following characteristics of the RCTs were extracted: (1) first author and publication year, (2) interventions (doses of dapagliflozin and the drugs used in combination), (3) characteristics of participants, (4) follow-up durations and (5) findings.

\section{Quality assessment}

We assessed the design, execution and reporting of the included RCTs according to the Cochrane risk of bias tool. ${ }^{16}$ The quality of each RCT was assessed by one reviewer and verified by another reviewer. Disagreement was resolved by discussion. The evidential level of each outcome was determined in accordance with the Grading of Recommendations Assessment, Development and Evaluation (GRADE) system ${ }^{17}$ and conducted with GRADE profiler 3.2 (http://tech.cochrane.org/ revman/gradepro).

\section{Data synthesis and analysis}

The meta-analysis of effect sizes was performed using both R 3.0.1 (http://www.r-project.org/) with the metaphor package (http://www.metafor-project.org/) and Review Manager 5.2 (http: http://ims.cochrane.org/ 
revman/). Other statistical tests and regression analysis were conducted using $\mathrm{R}$ 3.0.1. p Values $<0.05$ were considered statistically significant. Meta-analysis based on the random effects model was conducted for comparing the changes of HbAlc (\%), FPG (mmol/L) and body weight $(\mathrm{kg})$ between $10 \mathrm{mg}$ dapagliflozin arm and placebo arm. The continuous variables extracted from the included RCTs were adjusted mean differences (AMD) with $95 \%$ CI. The overall effect size was calculated as the mean difference of AMD, thus the mean differences in results stood for AMD. Subgroup analysis was conducted according to drug combinations (selected from metformin, insulin, glimepiride, pioglitazone and metformin/sitagliptin) and the durations of follow-up ( $\leq 24$ weeks or not). The effects of different follow-up durations were also assessed by meta-regression. Publication bias was evaluated using the Egger's regression test and a funnel plot of the effect sizes against the SE. Publication bias was adjusted using the trim-and-fill procedure. ${ }^{18}$ Heterogeneity was assessed with the $\mathrm{I}^{2}$ statistics, ${ }^{19}$ which is the proportion of total variance observed between the trials attributed to the differences between trials rather than to sampling error. $\mathrm{I}^{2}<25 \%$ was considered as low in heterogeneity and $\mathrm{I}^{2}>75 \%$ was of high heterogeneity.

\section{Sensitivity analysis}

Sensitivity analysis was performed to evaluate the robustness of the meta-analysis results. The RCTs with high risk of bias were excluded for sensitivity analysis. The sensitivity analysis evaluated the differences between overall results and results from the studies with low risk of bias. In addition, we excluded the interim results, that is, only using endpoint results of trials, to evaluate the robustness of the meta-analysis results.

\section{RESULTS}

\section{Study selection}

A total of 380 citations were assessed in the initial searching, of which 231 were identified via bibliographical databases and 149 were identified by supplementary search via Google and Google Scholar (figure 1). By screening the abstracts, we excluded 139 non-RCTs and seven pharmacokinetics and pharmacodynamics studies. Of the remaining 20 RCTs, 8 RCTs did not meet the inclusion criteria on interventions and comparators. Finally, a total number of 12 RCTs were included for quantitative synthesis and meta-analysis.

\section{Study characteristics}

The characteristics of the included 12 RCTs $^{20-31}$ are summarised in table 1 . The RCTs contained interventions of 2.5, 5 and $10 \mathrm{mg}$ add-on dapagliflozin. The eligible RCTs were also summarised according to their combined drugs: (1) $10 \mathrm{mg}$ dapdgliflozin plus metformin versus placebo plus metformin; (2) $10 \mathrm{mg}$ dapdgliflozin plus insulin versus placebo plus insulin; (3) $10 \mathrm{mg}$ dapdgliflozin plus glimepiride versus placebo plus glimepiride; (4) $10 \mathrm{mg}$ dapdgliflozin plus pioglitazone versus placebo plus pioglitazone; (5) $10 \mathrm{mg}$ dapdgliflozin plus metformin/sitagliptin versus placebo plus metformin/ sitagliptin. The participants in all RCTs were patients with T2DM ( $\geq 18$ years old). The outcomes measuring the effects of dapagliflozin were HbAlc (\%), FPG $(\mathrm{mmol} / \mathrm{L})$ and body weight $(\mathrm{kg})$.

The data extracted from the included RCTs for meta-analysis were sample sizes and changes from baselines, such as AMD and SD/SE. The mean differences were adjusted according to the last observation carried forward (LOCF) which was adopted in most RCTs. Hence the AMD extracted from the RCTs were subject to analysis of covariance (ANCOVA) model.

\section{Risk of bias within studies}

According to the Cochrane risk of bias tool, four RCTs had more than one item with unclear risk of bias. $^{24} 262831$ The common bias was the detection bias due to no report of blinding (figure 2). The average quality of the RCTs was acceptable. The GRADE evaluation indicated that the outcomes of HbAlc and FPG had high quality of the evidence. However, the quality of the evidence on body weight was moderate due to publication bias (table 2).

\section{Synthesis of results from individual studies $\mathrm{HbA1c}$}

Twelve RCTs with 3986 participants were included in the meta-analysis on the effect of dapagliflozin on changing the participants' HbA1c levels. There were 1996 participants in the intervention groups $(10 \mathrm{mg}$ dapagliflozin combined with five drugs) and 1990 participants in the control groups (placebo combined with corresponding drugs). The follow-up durations ranged from 12 to 104 weeks. A forest plot of HbA1c is presented in figure 3.

The differences of AMD between the intervention groups and the control groups ranged from $-0.8 \%$ to $-0.29 \%$. HbAlc levels decreased after supplement of dapagliflozin. The overall effect size in terms of mean difference was $-0.52 \%(\mathrm{Z}=-13.56, \mathrm{p}<0.001)$ with $95 \% \mathrm{CI}$ $(-0.60$, to -0.45$)$. The heterogeneity among the RCTs was moderate with $\mathrm{I}^{2}=56 \% \quad(\mathrm{Q}=29.54, \mathrm{p}=0.0055)$ and $95 \%$ CI $(19.9 \%$ to $75.8 \%)$. The funnel plot analysis showed no publication bias (figure 4) and the Egger's regression test was not significant in asymmetry $(\mathrm{t}=$ $-1.90, \mathrm{p}=0.08)$.

Subgroup meta-analyses were conducted by stratifying the five antidiabetic drugs (metformin, insulin, glimepiride, pioglitazone and metformin/sitagliptin) combined with dapagliflozin and the follow-up durations $(\leq 24$, $>24$ weeks). The effect sizes ranged from $-0.69 \%$ to $-0.47 \%$. The metformin plus metformin subgroup had the smallest effect size with a mean difference of $-0.47 \% \quad(\mathrm{Z}=-7.31, \mathrm{p}<0.001)$. The two duration subgroups did not differ much, with a mean difference $-0.53 \% \quad(\leq 24)$ and $-0.52 \% \quad(>24$ weeks; see online 


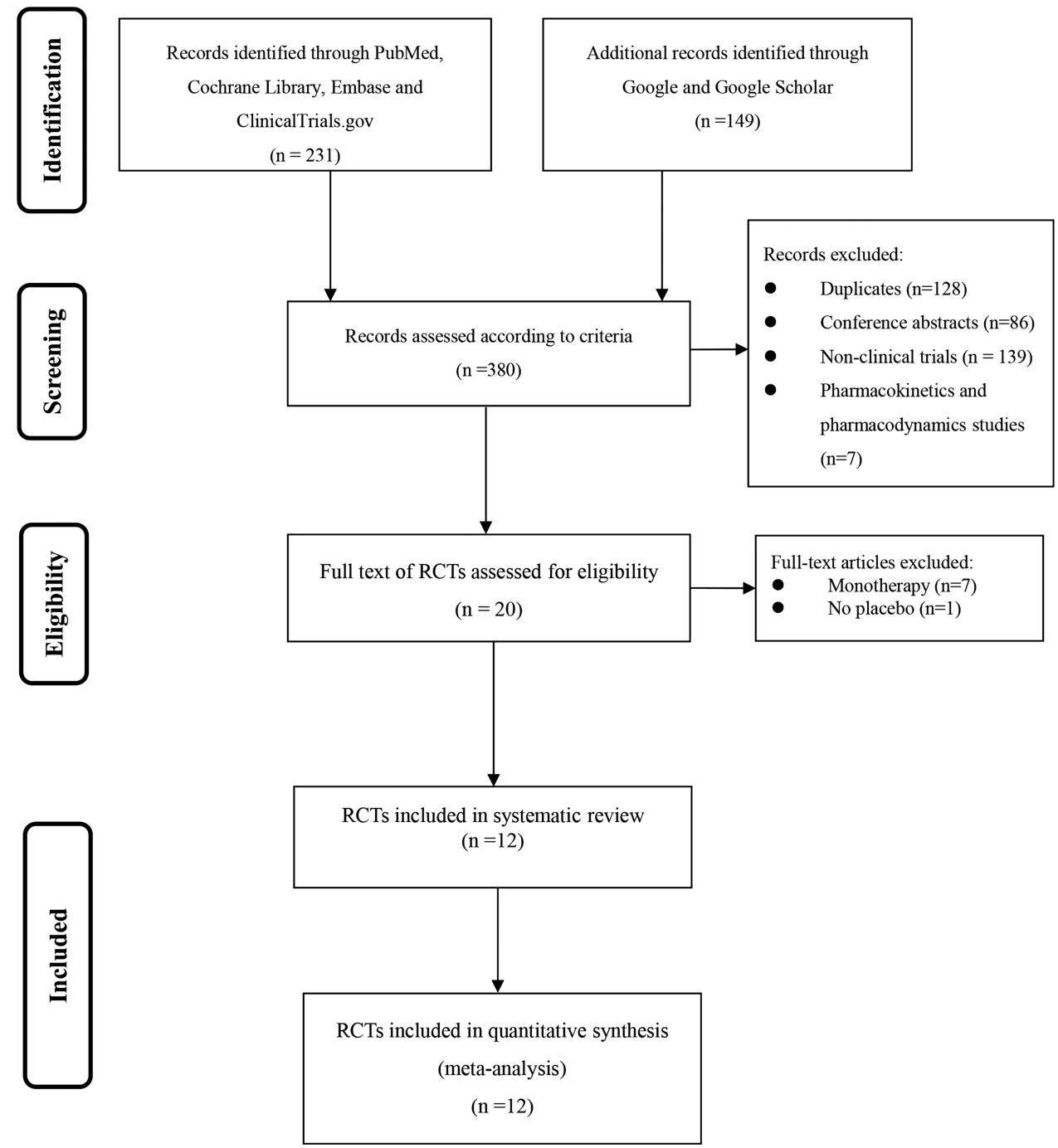

Figure 1 Flow diagram of study selection. RCT, randomised controlled trial.

supplementary appendix 1). The meta-regression on the overall follow-up durations (12th, 24th, 48th, 50th, 102nd and 104th weeks) did not give any statistically significant results (table 3 ).

\section{Fasting plasma glucose}

All 12 included RCTs with 3620 participants reported the effect sizes of dapagliflozin on FPG. There were 1817 participants in the intervention groups (10 $\mathrm{mg}$ dapagliflozin combined with the five types of drugs) and 1803 participants in the control groups (placebo combined with the corresponding drugs). The follow-up durations ranged from 12 to 104 weeks. As depicted in a forest plot of FPG (figure 5), all the RCTs showed the decreases in FPG after the add-on of dapagliflozin. The overall mean difference between the intervention groups and the control groups was $-1.13 \mathrm{mmol} / \mathrm{L}(\mathrm{Z}=-11.12, \mathrm{p}<0.001)$ with $95 \%$ CI $(-1.33$ to -0.93$)$. The heterogeneity among these RCTs was moderate with $\mathrm{I}^{2}=53.8 \%(\mathrm{Q}=23.81, \mathrm{p}=0.0135)$. The funnel plot analysis also showed no publication bias (figure 4) and the Egger's regression test was not significant in asymmetry $(\mathrm{t}=1.55, \mathrm{p}=0.15)$.
Subgroup meta-analyses were conducted on five different combined drugs and follow-up durations. The effect sizes of the drug subgroups ranged from $-1.47 \mathrm{mmol} / \mathrm{L}$ (pioglitazone group) to $-0.93 \mathrm{mmol} / \mathrm{L}$ (metformin group). In the follow-up duration subgroups, the mean differences were -1.13 ( $>24$ weeks) and $-1.36 \mathrm{mmol} / \mathrm{L}$ ( $\leq 24$ weeks; see online supplementary appendix 2 ). The meta-regression showed a significant effect of the overall follow-up durations (12th, 24th, 48th, 50th, 102nd and 104 th weeks) with $R^{2}=0.9704$ and $p<0.001$. The estimated coefficient on follow-up duration was -1.52 with SE 0.12 and $95 \%$ CI $(-1.75$ to -1.29 ; table 3$)$.

\section{Body weight}

Twelve RCTs with a total of 4008 participants reported the effect sizes of dapagliflozin on body weight changes. The RCTs included 2005 participants in the intervention groups $(10 \mathrm{mg}$ dapagliflozin combined with the five types of drugs) and 2003 participants in the control groups (placebo combined with the corresponding drugs). The follow-up durations ranged from 12 to 104 weeks. A forest plot showed decreases in body 


\begin{tabular}{|c|c|c|c|c|c|c|c|c|}
\hline \multirow[b]{2}{*}{ Study } & \multirow[b]{2}{*}{ Treatments } & \multirow[b]{2}{*}{$\mathbf{N}$} & \multicolumn{4}{|c|}{ Participants' characteristics ${ }^{*}$} & \multirow[b]{2}{*}{ Weeks (max) } & \multirow[b]{2}{*}{ Findings } \\
\hline & & & Age & HbA1c (\%) & $\begin{array}{l}\text { BMI or weight } \\
\left(\mathrm{kg} / \mathrm{m}^{2} \text { or } \mathrm{kg} t\right)\end{array}$ & $\begin{array}{l}\text { FPG (mmol/L or } \\
\mathrm{mg} / \mathrm{dL} \neq)\end{array}$ & & \\
\hline \multirow[t]{4}{*}{ Bailey et a ${ }^{20}$} & PLA & 137 & $53.7(10.3)$ & $8.11(0.96)$ & $31.8(5.3)$ & $9.19(2.57)$ & \multirow[t]{4}{*}{24} & \multirow{8}{*}{$\begin{array}{l}\text { Dapagliflozin+metformin } \\
\text { enhanced glycaemic } \\
\text { control and lowered body } \\
\text { weight } \\
\text { Dapagliflozin+metformin for }\end{array}$} \\
\hline & $2.5 \mathrm{mg}$ DAPA & 137 & $55(9.3)$ & $7.99(0.90)$ & $31.6(4.8)$ & 8.96 (2.39) & & \\
\hline & $5 \mathrm{mg}$ DAPA & 137 & $54.3(9.4)$ & $8.17(0.96)$ & $31.4(5.0)$ & $9.39(2.72)$ & & \\
\hline & $10 \mathrm{mg}$ DAPA & 135 & $52.7(9.9)$ & $7.92(0.82)$ & $31.2(5.1)$ & $8.66(2.15)$ & & \\
\hline \multirow[t]{4}{*}{ Bailey et $a^{21}$} & $\mathrm{PLA}+\mathrm{MET}$ & 137 & NA & $8.12(0.96)$ & $87.74(19.24) \dagger$ & $9.19(2.58)$ & \multirow[t]{4}{*}{102} & \\
\hline & $2.5 \mathrm{mg}$ DAPA+MET & 137 & NA & $7.99(0.90)$ & $84.90(17.77) \dagger$ & 8.96 (2.39) & & \\
\hline & $5 \mathrm{mg}$ DAPA+MET & 137 & NA & $8.17(0.96)$ & $84.73(16.26) \dagger$ & $9.39(2.72)$ & & \\
\hline & 10 mg DAPA+MET & 135 & NA & $7.92(0.82)$ & $86.28(17.53) \dagger$ & $8.66(2.15)$ & & \\
\hline \multirow[t]{2}{*}{ Bolinder et al ${ }^{22}$} & PLA+MET & 91 & $60.8(6.9)$ & $8.11(0.96)$ & 31.7 (3.9) & $8.3(1.4)$ & \multirow[t]{2}{*}{24} & \multirow{2}{*}{$\begin{array}{l}\text { Dapagliflozin+metformin } \\
\text { reduced total body weight }\end{array}$} \\
\hline & 10 mg DAPA+MET & 89 & $60.6(8.2)$ & $7.99(0.90)$ & $32.1(3.9)$ & $8.2(1.4)$ & & \\
\hline \multirow[t]{2}{*}{ Bolinder et $a f^{33}$} & PLA+MET & 91 & NA & 7.16 & $90.9 \dagger$ & 8.21 & \multirow[t]{2}{*}{102} & Dapagliflozin+metformin \\
\hline & 10 mg DAPA+MET & 91 & NA & 7.19 & $92.1 \dagger$ & 8.3 & & $\begin{array}{l}\text { enhanced } \\
\text { glycaemic control and reduced } \\
\text { body weight }\end{array}$ \\
\hline \multirow[t]{7}{*}{ Henry et $a^{24}$} & Study 1 & & & & & & \multirow[t]{7}{*}{24} & \multirow{7}{*}{$\begin{array}{l}\text { Dapagliflozin+metformin was } \\
\text { effective in } \\
\text { reducing } \mathrm{HbA1c}, \mathrm{FPG} \text { and } \\
\text { weight }\end{array}$} \\
\hline & $5 \mathrm{mg}$ DAPA+PLA & 203 & $52.3(10.2)$ & $9.1(1.4)$ & $86.2(21.1) \dagger$ & 10.59 (3.14) & & \\
\hline & $\mathrm{MET}+\mathrm{PLA}$ & 201 & $51.8(9.8)$ & 9.2 (1.3) & $85.6(20.0) \dagger$ & 10.94 (3.53) & & \\
\hline & $\begin{array}{l}5 \text { mg DAPA+MET } \\
\text { Study } 2\end{array}$ & 194 & $51.7(9.3)$ & $9.2(1.3)$ & $84.1(19.5) \dagger$ & $10.76(3.12)$ & & \\
\hline & $10 \mathrm{mg}$ DAPA+PLA & 219 & $51.1(11.5)$ & $9.1(1.3)$ & 88.5 (19.3)† & 10.99 (3.43) & & \\
\hline & $\mathrm{MET}+\mathrm{PLA}$ & 208 & $52.7(10.4)$ & $9.1(1.3)$ & $87.2(19.4) \dagger$ & $10.57(3.00)$ & & \\
\hline & 10 mg DAPA+MET & 211 & $51.0(10.1)$ & $9.1(1.3)$ & $88.4(19.7) \dagger$ & $10.52(3.22)$ & & \\
\hline \multirow[t]{2}{*}{ Ljunggren et $a{ }^{25}$} & PLA+MET & 91 & $60.8(6.9)$ & $7.16(0.53)$ & $31.7(3.9)$ & $8.3(1.4)$ & \multirow[t]{2}{*}{50} & \multirow{2}{*}{$\begin{array}{l}\text { Dapagliflozin+metformin did } \\
\text { not affect markers of } \\
\text { bone formation and resorption }\end{array}$} \\
\hline & 10 mg DAPA+MET & 89 & $60.6(8.2)$ & $7.19(0.44)$ & 32.1 (3.9) & $8.2(1.4)$ & & \\
\hline \multirow{3}{*}{$\begin{array}{l}\text { Rosenstock } \\
\text { et af6 }\end{array}$} & $\geq 30 \mathrm{mg} \mathrm{PIO}+\mathrm{PLA}$ & 139 & $53.5(11.4)$ & $8.34(1.00)$ & NA & $8.92(2.61)$ & \multirow[t]{3}{*}{48} & Dapagliflozin+pioglitaz one \\
\hline & $\geq 30 \mathrm{mg} \mathrm{PIO}+5 \mathrm{mg}$ DAPA & 141 & $53.2(10.9)$ & $8.40(1.03)$ & NA & $9.36(2.98)$ & & further enhanced glycaemic \\
\hline & $\geq 30 \mathrm{mg} \mathrm{PIO}+10 \mathrm{mg}$ DAPA & 140 & $53.8(10.4)$ & $8.37(0.96)$ & NA & $9.15(2.57)$ & & $\begin{array}{l}\text { control without } \\
\text { pioglitazone-related body } \\
\text { weight gain }\end{array}$ \\
\hline \multirow[t]{4}{*}{ Strojek et $a R^{7}$} & $\mathrm{PLA}+\mathrm{GLI}$ & 145 & $60.3(10.16)$ & $8.15(0.74)$ & NA & $9.58(2.07)$ & \multirow[t]{4}{*}{24} & Dapagliflozin+glimepiride \\
\hline & $2.5 \mathrm{mg} \mathrm{DAPA}+\mathrm{GLI}$ & 154 & $59.9(10.14)$ & $8.11(0.75)$ & NA & $9.56(2.13)$ & & significantly enhanced \\
\hline & 5 mg DAPA+GLI & 142 & $60.2(9.73)$ & $8.12(0.78)$ & NA & 9.68 (2.12) & & glycaemic control and reduced \\
\hline & $10 \mathrm{mg} \mathrm{DAPA}+\mathrm{GLI}$ & 151 & $58.9(8.32)$ & $8.07(0.79)$ & NA & $9.55(2.04)$ & & body weight \\
\hline \multirow[t]{3}{*}{ Wilding, et $a$ P $^{8}$} & PLA+INS & 23 & $58.4(6.5)$ & $8.4(0.9)$ & $34.8(4.6)$ & $165.9(51.5) \ddagger$ & 12 & Dapagliflozin+insulin improved \\
\hline & $10 \mathrm{mg}$ DAPA+INS & 24 & $55.7(9.2)$ & $8.4(0.7)$ & $35.5(3.6)$ & $156.0(39.0) \ddagger$ & & glycaemic control and lowered \\
\hline & $20 \mathrm{mg}$ DAPA+INS & 24 & $56.1(10.6)$ & $8.5(0.9)$ & $36.2(4.6)$ & $161.6(55.0) \ddagger$ & & body weight \\
\hline Wilding, et $a{ }^{29}$ & PLA+INS & 193 & $58.8(8.6)$ & $8.47(0.77)$ & $33.1(5.9)$ & $9.5(3.2)$ & 48 & Dapagliflozin+insulin \\
\hline & $2.5 \mathrm{mg}$ DAPA+INS & 202 & $59.8(7.6)$ & $8.46(0.78)$ & $33.0(5.0)$ & $10.0(3.3)$ & & enhanced glycaemic control, \\
\hline
\end{tabular}




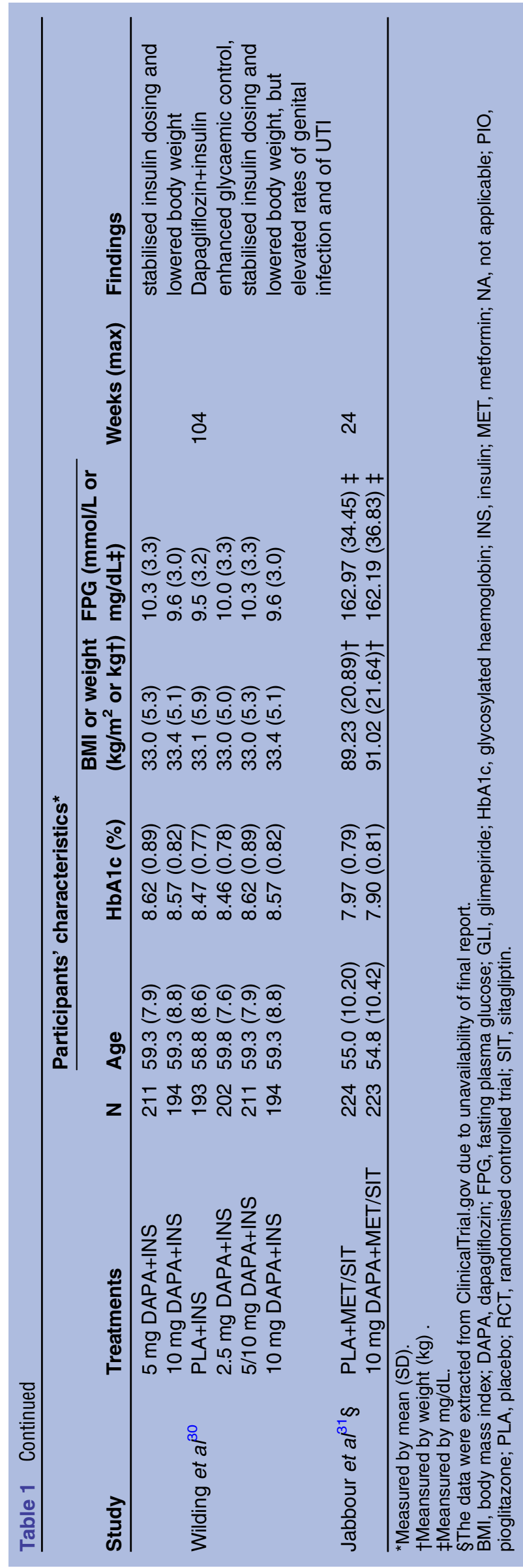

weight after the intervention of dapagliflozin (figure 6). The decreases ranged from -3.33 to $-1.54 \mathrm{~kg}$. The overall mean difference between the intervention groups and the control groups was $-2.10 \mathrm{~kg}(\mathrm{Z}=-18.77$, $\mathrm{p}<0.001)$ with $95 \%$ CI $(-2.32$ to -1.88$)$. The heterogeneity among RCTs was not significant with $\mathrm{I}^{2}=12 \%$ $(\mathrm{Q}=14.73, \mathrm{p}=0.32)$. The funnel plot analysis revealed some publication bias (figure 4) and the Egger's regression test was significant in asymmetry $(\mathrm{t}=-3.11$, $\mathrm{p}=0.009$ ).

The subgroup meta-analyses were conducted on five different combinations of drugs and two follow-up durations. The effect sizes of the drug subgroups ranged from -2.45 to $-1.54 \mathrm{~kg}$ with insulin the most effective and glimepiride the least. The results of follow-up duration subgroups showed that the differences of effect sizes ranged from $-2.63(\leq 24)$ to $-1.92 \mathrm{~kg}$ (> 24 weeks; see online supplementary appendix 3 ), which implied that dapagliflozin has the efficacy of long-term clinical outcome. The result from meta-regression showed a significant effect of the follow-up durations (12th, 24th, 48th, 102nd and 104th weeks) with $\mathrm{R}^{2}=1$ and $\mathrm{p}<0.01$. The estimated coefficient was -1.61 with SE 0.18 and $95 \%$ CI $(-1.97$ to -1.26 ; table 3$)$.

\section{Risk of bias across studies}

The funnel plots of HbA1c, FPG and body weight checked the possibility of publication bias (figure 4). The results from the Egger's regression found a significant publication bias in the outcome of body weight ( $\mathrm{t}=$ -3.11, $\mathrm{p}=0.0091$ ). After the trim-and-fill adjustment on the funnel plot, the estimated mean difference was $-1.94 \mathrm{~kg}$ with $95 \%$ CI $(-2.18$ to-1.70). However, there was no significant publication bias in the result of HbA1c $(\mathrm{t}=-1.90, \mathrm{p}=0.08)$ and FPG $(\mathrm{t}=1.55, \mathrm{p}=0.152)$.

\section{Sensitivity analysis}

By the Cochrane risk of bias tool, we found that four RCTs had more than one items with unclear risk of bias. $^{24} 262831$ When we excluded those RCTs, the overall effect size of $\mathrm{HbAlc}$ changed to $-0.50 \%$ with $95 \%$ CI $(-0.61$ to -0.40$)$. The effect size of FPG became $-1.08 \mathrm{mmol} / \mathrm{L}$ with $95 \%$ CI $(-1.29$ to -0.87$)$ and the result of body weight $-2.08 \mathrm{~kg}$ with $95 \%$ CI $(-2.36$ to -1.82 ; see online supplementary appendix 4 ). The new results did not differ much from the previous ones, that is $-0.52 \%$ in HbAlc, $-1.13 \mathrm{mmol} / \mathrm{L}$ in $\mathrm{FPG}$ and $-2.10 \mathrm{~kg}$ in body weight (figures 3,5 and 6 ).

In addition, we found that four RCTs published only interim results. ${ }^{20} 222529$ Hence, we excluded the interim RCTs to re-examine the robustness of our meta-analysis. The data from eight RCTs ${ }^{21} 23 \quad 24$ 26-28 3031 with final results were kept for sensitivity analysis. The overall mean differences came to $-0.56 \%$ in $\mathrm{HbA1c},-1.11 \mathrm{mmol} / \mathrm{L}$ in FPG, and $-2.23 \mathrm{~kg}$ in body weight, which did not change too much (see online supplementary appendix 5). 
Figure 2 Cochrane risk of bias: (A) graph and (B) summary.

A

Random sequence generation (selection bias)

Allocation concealment (selection bias) Blinding of participants and personnel (performance bias) Blinding of outcome assessment (detection bias)

Incomplete outcome data (attrition bias)

Selective reporting (reporting bias)

Low risk of bias Unclear risk of bias

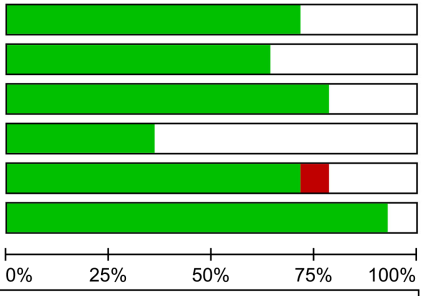

$\square$ High risk of bias

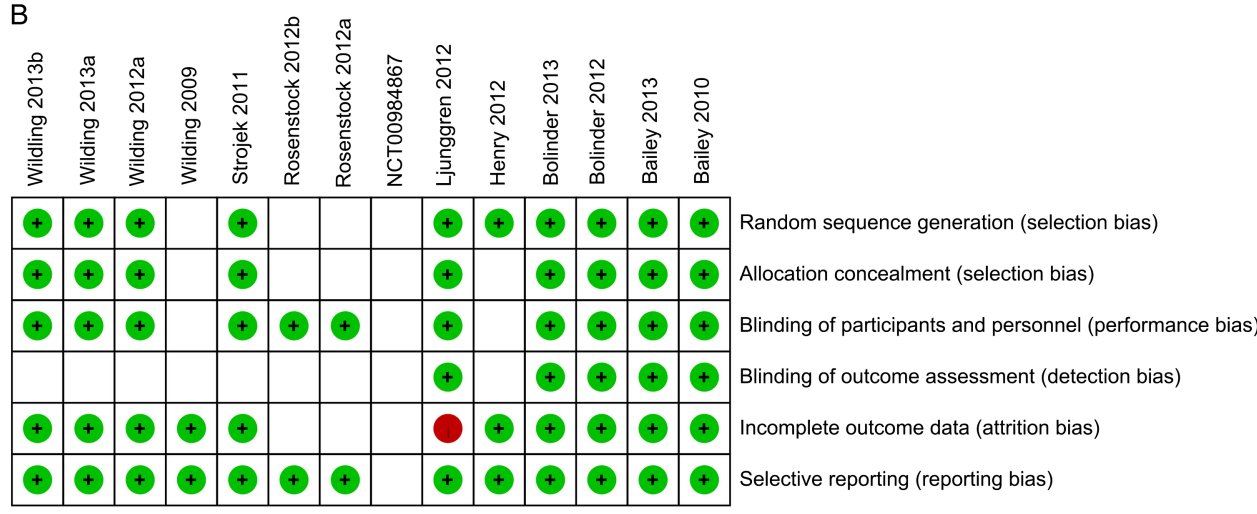

\section{DISCUSSION}

This study of systematic review and meta-analysis on the efficacy of dapagliflozin in combination with antidiabetic drugs followed the PRISMA guideline and was registered with the PROSPERO database before the conduct. Subgroup meta-analyses and sensitivity analyses were also conducted to ensure the robustness of the evidence.

Table 2 GRADE assessment of the outcomes (HbA1c, FPG and body weight)

\section{0 mg Dapagliflozin arm compared with PLA arm for GRADE}

Patient or population: patients with type 2 diabetes mellitus

Intervention: $10 \mathrm{mg}$ dapagliflozin combined with antidiabetic drugs

Comparison: placebo combined with antidiabetic drugs

\begin{tabular}{|c|c|c|c|c|}
\hline \multirow[b]{2}{*}{ Outcomes } & \multicolumn{2}{|c|}{ Illustrative comparative risks* $(95 \% \mathrm{Cl})$} & \multirow[b]{2}{*}{$\begin{array}{l}\text { Number of } \\
\text { participants } \\
\text { (studies) }\end{array}$} & \multirow[b]{2}{*}{$\begin{array}{l}\text { Quality of the } \\
\text { evidence } \\
\text { (GRADE) }\end{array}$} \\
\hline & $\begin{array}{l}\text { Assumed risk } \\
\text { Placebo combined with } \\
\text { antidiabetic drugs }\end{array}$ & $\begin{array}{l}\text { Corresponding risk } \\
10 \text { mg Dapagliflozin } \\
\text { combined with antidiabetic } \\
\text { drugs }\end{array}$ & & \\
\hline $\begin{array}{l}\text { HbA1c (\%) } \\
\text { Follow-up: } \\
\text { 12-104 weeks }\end{array}$ & $\begin{array}{l}\text { The mean } \mathrm{HbA} 1 \mathrm{c} \text { ranged } \\
\text { across control groups from } \\
\mathbf{- 1 . 4 4} \text { to } 0.09 \%\end{array}$ & $\begin{array}{l}\text { The mean } \mathrm{HbA} 1 \mathrm{c} \text { in the } \\
\text { intervention groups was } \\
\mathbf{0 . 5 2} \text { lower ( } 0.6 \text { to } 0.45 \text { lower) }\end{array}$ & $\begin{array}{l}3986 \\
\text { (14 studies) }\end{array}$ & $\begin{array}{l}\oplus \oplus \oplus \oplus \\
\text { High }\end{array}$ \\
\hline $\begin{array}{l}\text { FPG }(\mathrm{mmol} / \mathrm{L}) \\
\text { Follow-up: } \\
\text { 12-104 weeks }\end{array}$ & $\begin{array}{l}\text { The mean FPG ranged } \\
\text { across control groups from } \\
-\mathbf{1 . 9 3} \text { to } 0.99 \mathrm{mmol} / \mathrm{L}\end{array}$ & $\begin{array}{l}\text { The mean FPG in the } \\
\text { intervention groups was } \\
\mathbf{1 . 1 3} \text { lower ( } 1.33 \text { to } 0.93 \text { lower) }\end{array}$ & $\begin{array}{l}3620 \\
\text { (12 studies) }\end{array}$ & $\begin{array}{l}\oplus \oplus \oplus \oplus \\
\text { High }\end{array}$ \\
\hline $\begin{array}{l}\text { Body weight }(\mathrm{kg}) \\
\text { Follow-up: } \\
\text { 12-104 weeks }\end{array}$ & $\begin{array}{l}\text { The mean body weight } \\
\text { ranged across control groups } \\
\text { from } \\
-2.12 \text { to } 2.99 \mathbf{~ k g}\end{array}$ & $\begin{array}{l}\text { The mean body weight in the } \\
\text { intervention groups was } \\
\mathbf{2 . 1 0} \text { lower ( } 2.32 \text { to } 1.88 \text { lower) }\end{array}$ & $\begin{array}{l}4008 \\
\text { (14 studies) }\end{array}$ & $\begin{array}{l}\oplus \oplus \oplus \ominus \\
\text { Moderate }\end{array}$ \\
\hline
\end{tabular}

GRADE Working Group grades of evidence.

High quality. Further research is very unlikely to change our confidence in the estimate of effect.

Moderate quality Further research is likely to have an important impact on our confidence in the estimate of effect and may change the estimate.

Low quality. Further research is very likely to have an important impact on our confidence in the estimate of effect and is likely to change the estimate.

Very low quality. We are very uncertain about the estimate.

*The basis for the assumed risk (eg, the median control group risk across studies) is provided in footnotes. The corresponding risk (and its

$95 \% \mathrm{Cl}$ ) is based on the assumed risk in the comparison group and the relative effect of the intervention (and its $95 \% \mathrm{Cl}$ ).

FPG, fasting plasma glucose; HbA1c, glycosylated haemoglobin; PLA, placebo. 


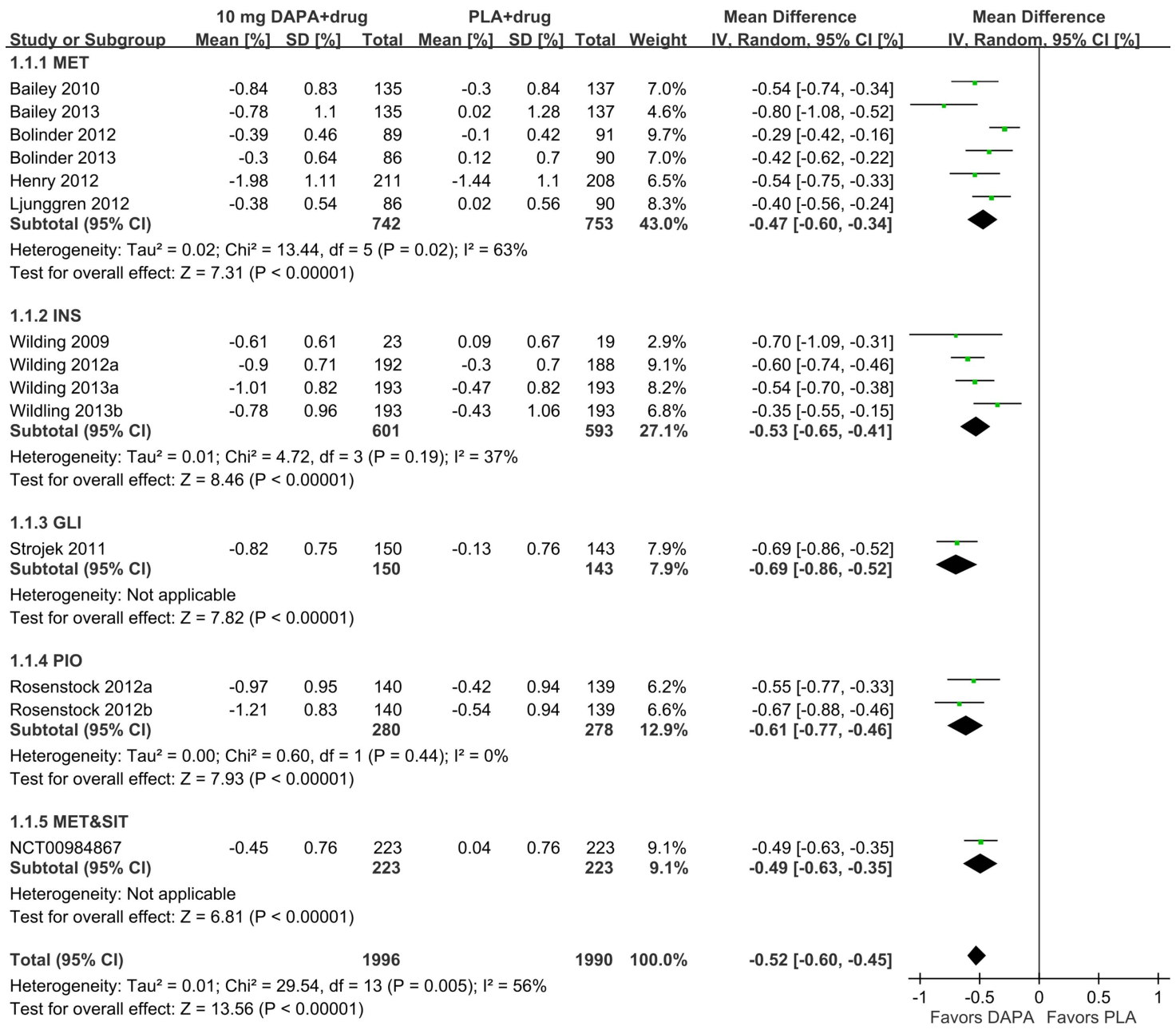

Figure 3 Forest plots of overall effect size of glycosylated haemoglobin and subgroup meta-analysis of different combined drugs. GLI, glimepiride; INS, insulin; MET, metformin; PIO, pioglitazone; SIT, sitagliptin.

In agreement with another meta-analysis on monotherapy of T2DM with dapagliflozin, ${ }^{13}$ one network meta-analysis on dapaliflozin in combination with metformin ${ }^{14}$ and three other meta-analyses on SGLT2 inhibitors in general, ${ }^{3}{ }^{11-12}$ we found dapagliflozin beneficial in glycaemic control of T2DM. In contrast to these meta-analyses, we did a PRISMA-compliant meta-analysis, including additional sensitivity analyses and publication bias analyses, on the efficacy of dapagliflozin combined with another antidiabetic drug.

This meta-analysis indicated that dapagliflozin as an add-on drug to conventional antidiabetic drugs did improve the control of the HbAlc and FPG levels in T2DM participants. Individual RCTs indicated that insulin and pioglitazone increased body weight, ${ }^{26} 2930$ which would be deemed harmful to T2DM participants. Our meta-analysis confirmed a consensus that the body weight of T2DM participants was well controlled under treatment of dapagliflozin in combination with other antidiabetic drugs.

Even though the Egger's regression test showed publication bias in the outcome of body weight, dapagliflozin as an add-on drug still reduced body weight after a trim-and-fill procedure on the funnel plot. Although the publication bias on body weight was statistically significant, it might not indicate a strong clinical significance because body weight was not the primary outcome in the RCTs. Subgroup meta-analyses showed that dapagliflozin enhanced the effects of conventional antidiabetic drugs on controlling the HbA1c, FPG and body weight. A meta-regression further suggested that dapagliflozin had long-term effects on controlling FPG and body weight of T2DM participants.

There were limitations in this meta-analysis that have to be overcome in later studies. Four RCTs published only short follow-up periods. ${ }^{20} 222529$ Considering the consistency in dosage, we used $10 \mathrm{mg}$ dapagliflozin data only. The limited number of RCTs might overestimate the $\mathrm{R}^{2}$ in meta-regression. In this meta-analysis, most RCTs $^{20}$ 22-24 26-29 31 used LOCF methods to impute missing data. The combination of LOCF imputation with exclusion of postrescue data could lead to overstated results $^{32}$ and cause low estimates of SEs and $p$ values. ${ }^{33}$ All the included RCTs were sponsored by Bristol-Myers Squibb $^{20} 21242628$ or AstraZeneca ${ }^{22} 232527$ 29-31 which might introduce some potential bias, due to a concern 
Figure 4 Funnel plots after trim-and-fill adjustment and the Egger's regression test results on

(A) glycosylated haemoglobin,

(B) fasting plasma glucose, and

(C) body weight.
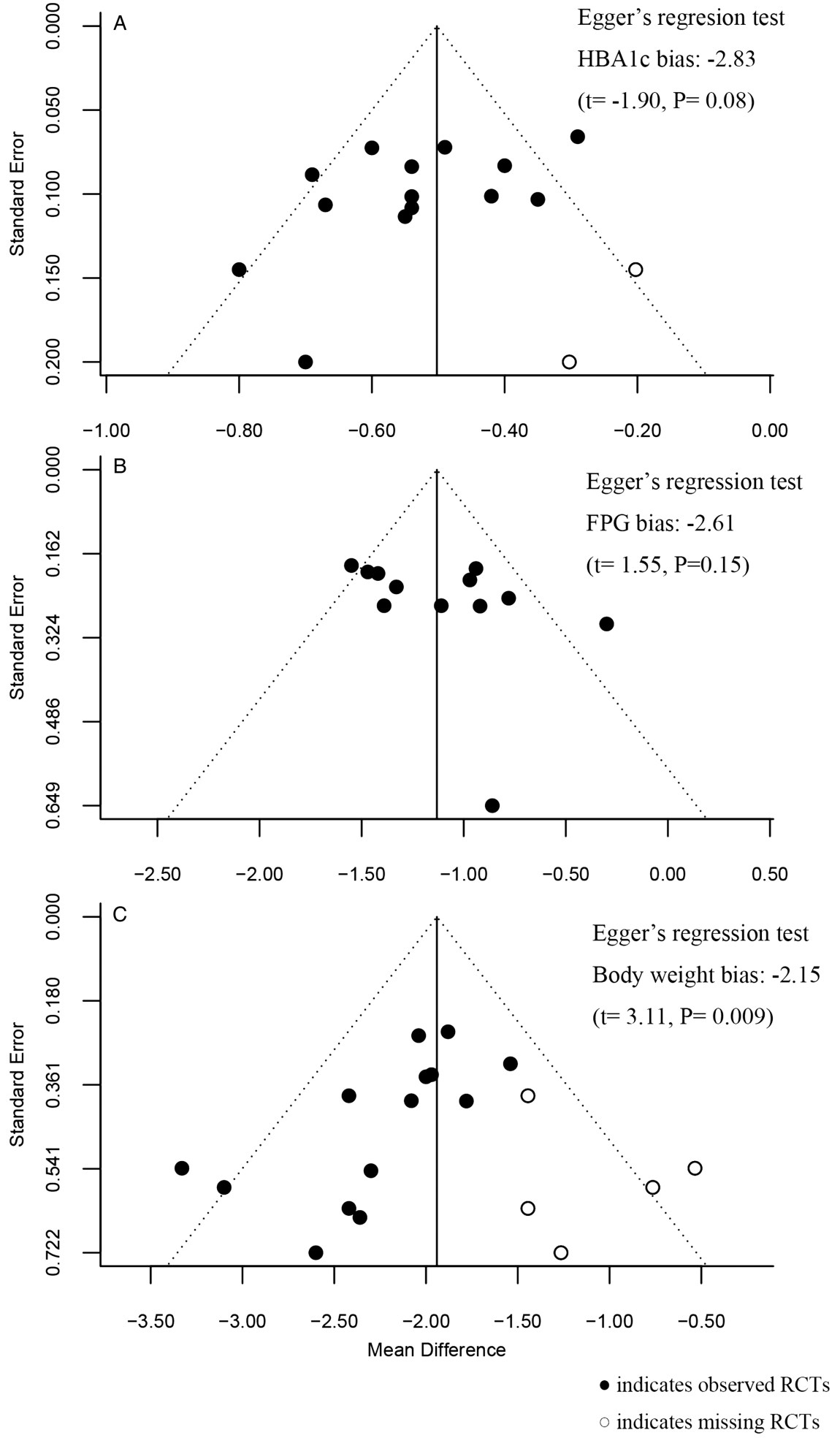

Table 3 Meta-regression results of the long-term outcomes (HbA1c, FPG, body weight)

\begin{tabular}{|c|c|c|c|c|c|c|}
\hline & \multicolumn{2}{|l|}{ HbA1c } & \multicolumn{2}{|l|}{ FPG } & \multicolumn{2}{|l|}{ Body weight } \\
\hline & Estimate (SE) & $95 \% \mathrm{Cl}$ & Estimate (SE) & $95 \% \mathrm{Cl}$ & Estimate (SE) & $95 \% \mathrm{Cl}$ \\
\hline $\begin{array}{l}\text { Intercept } \\
\text { Week }\end{array}$ & $\begin{array}{l}-0.55(0.07)^{\star} \\
0.001(0.001)\end{array}$ & $\begin{array}{l}(-0.68 \text { to }-0.41) \\
(-0.002 \text { to } 0.003)\end{array}$ & $\begin{array}{l}-1.52(0.12)^{\star} \\
-0.01(0.002)^{\star}\end{array}$ & $\begin{array}{l}(-1.75 \text { to }-1.29) \\
(0.004 \text { to } 0.012)\end{array}$ & $\begin{array}{l}-1.61(0.18)^{\star} \\
-0.01(0.004)^{\star}\end{array}$ & $\begin{array}{l}(-1.97 \text { to }-1.26) \\
(-0.02 \text { to } 0.01)\end{array}$ \\
\hline
\end{tabular}


$10 \mathrm{mg}$ DAPA+drug

PLA+drug

Mean Difference

Mean Difference

Study or Subgroup Mean [mmol/L] SD [mmol/L] Total Mean [mmol/L] SD [mmol/L] Total Weight IV. Random. 95\% CI [mmol/L] IV. Random. 95\% Cl [mmol/L]

1.2.1 MET

Bailey 2010

Bailey 2013

Bolinder 2013

Henry 2012

Wilding 2013a

Wildling $2013 \mathrm{~b}$

$\begin{array}{rrr}-1.3 & 1.78 & 13 \\ -1.36 & 1.72 & 13 \\ -0.96 & 1.25 & 89 \\ -3.35 & 2.04 & 21 \\ -1.42 & 2.56 & 194 \\ -1.3 & 2.77 & 194\end{array}$

$-0.33$

$\begin{array}{rrrr}-0.33 & 1.73 & 137 & 9.5 \% \\ -0.58 & 2.33 & 137 & 8.3 \% \\ -0.02 & 1.31 & 91 & 10.3 \%\end{array}$

$\begin{array}{rrrr}-0.02 & 1.31 & 91 & 10.3 \%\end{array}$

$\begin{array}{llll}-1.93 & 2.06 & 208 & 10.0 \%\end{array}$

$2.62 \quad 193 \quad 7.8 \%$

$3.08 \quad 193 \quad 6.8 \%$

Heterogeneity: Tau $^{2}=0.06 ; \mathrm{Chi}^{2}=10.75, \mathrm{df}=5(\mathrm{P}=0.06) ; \mathrm{I}^{2}=53 \%$

$-1$

$\begin{array}{rr}193 & 6.8 \% \\ 959 & 52.6 \%\end{array}$

Test for overall effect: $Z=6.71(P<0.00001)$

1.2.2 INS

$\begin{array}{llllllll}\text { Wilding } 2009 & 0.13 & 2.17 & 23 & 0.99 & 2.18 & 22 & 2.1 \%\end{array}$

$\begin{array}{llllllll}\text { Wilding 2012a } & -1.21 & 2.49 & 183 & 0.18 & 2.49 & 177 & 7.8 \%\end{array}$

Subtotal $(95 \% \mathrm{Cl})$

206
2.49

$\begin{array}{rr}2.49 \quad 177 & 7.8 \% \\ 199 & 9.9 \%\end{array}$

$-0.97[-1.39,-0.55]$

$-0.78[-1.27,-0.29]$

$-0.94[-1.31,-0.57]$

$-1.42[-1.81,-1.03]$

$-0.92[-1.44,-0.40]$

$-0.30[-0.88,0.28]$

$-0.93[-1.20,-0.66]$

Heterogeneity: Tau $^{2}=0.00 ; \mathrm{Chi}^{2}=0.57, \mathrm{~d}=1$
Test for overall effect: $Z=5.41(\mathrm{P}<0.00001)$

1.2.3 GLI

Strojek 2011

Subtotal $(95 \%$ C

$\begin{array}{rr}-1.58 \quad 1.7 \quad 150 \\ & 150\end{array}$

150
150

$\begin{array}{lll}1.69 \quad 145 & 10.1 \%\end{array}$

.

Test for overall effect: $Z=7.45(P<0.00001)$

1.2.4 PIO

$\begin{array}{llll}\text { Rosenstock 2012a } & -1.64 & 1.89 & 140\end{array}$

$\begin{array}{lccc}\text { Rosenstock 2012b } & -1.84 & 2.01 & 140 \\ \text { Subtotal }(95 \% \mathrm{Cl}) & & 280 \\ \text { Heterogeneity: } \mathrm{Tau}^{2}=0.00 ; \mathrm{Chi}^{2}=0.40, \mathrm{df}=1(\mathrm{P}=0.53) ; \mathrm{I}^{2}=0 \%\end{array}$

Test for overall effect: $Z=7.21(P<0.00001)$

1.2.5 MET\&SIT

Subtotal $(95 \% \mathrm{Cl})$

$\begin{array}{lll}-1.34 & 1.95 \quad 223\end{array}$

0.21

.21

$-0.86[-2.13,0.41]$

$-1.39[-1.90,-0.88]$

teterogeneity: Not applicable

Test for overall effect: $Z=8.38(P<0.00001)$

Total $(95 \% \mathrm{Cl})$

1817

Heterogeneity: $\mathrm{Tau}^{2}=0.06 ; \mathrm{Chi}^{2}=23.81, \mathrm{df}=11(\mathrm{P}=0.01) ; \mathrm{I}^{2}=54 \%$

Test for overall effect: $Z=11.12(P<0.00001)$

$1803 \quad 100.0 \%$

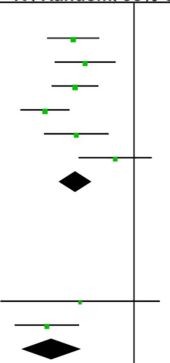

Figure 5 Forest plots of overall effect size of fasting plasma glucose and subgroup meta-analysis of different combined drugs. GLI, glimepiride; INS, insulin; MET, metformin; PIO, pioglitazone; SIT, sitagliptin.

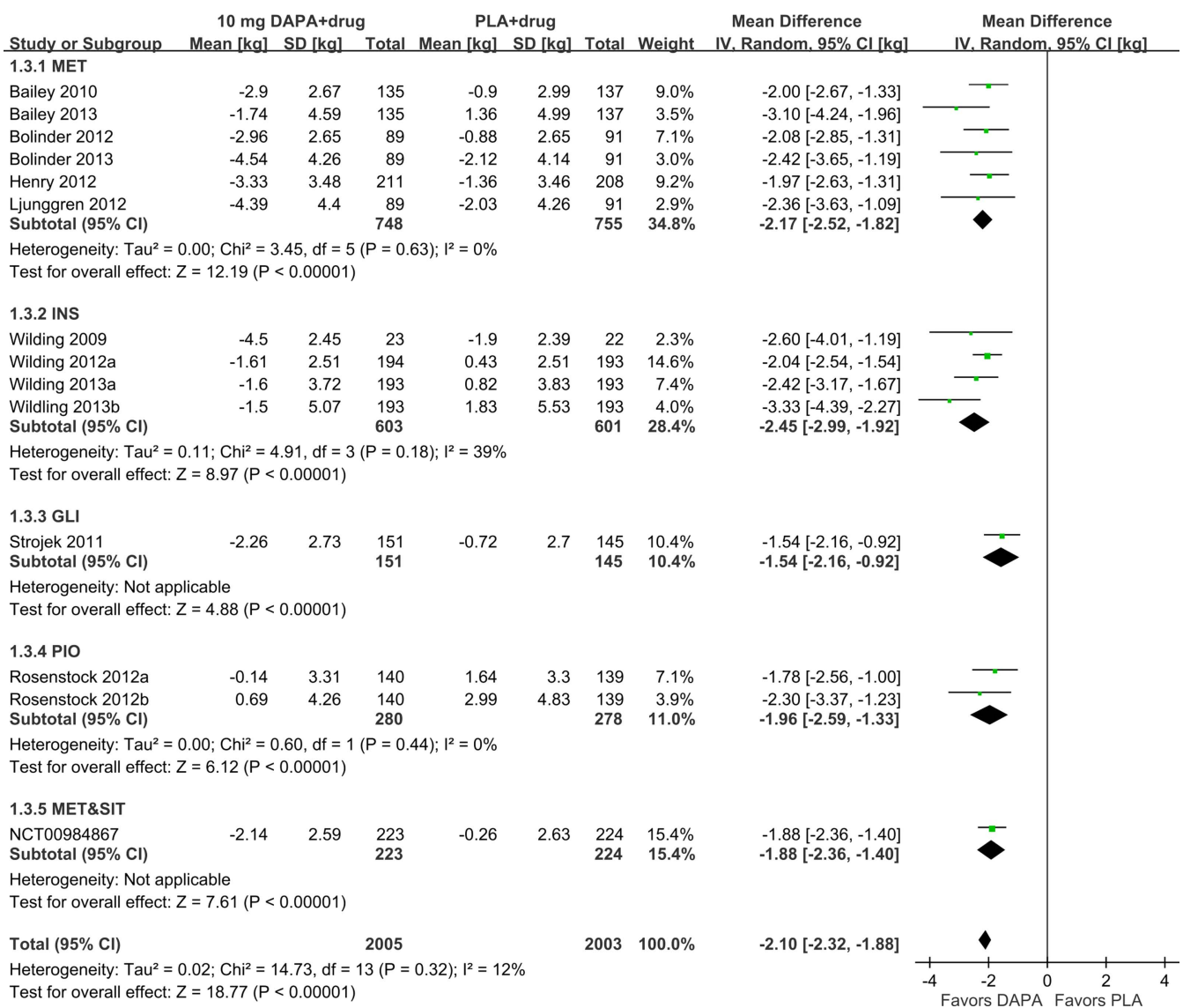

Figure 6 Forest plots of overall effect size of body weight and subgroup meta-analysis of different combined drugs. GLI, glimepiride; INS, insulin; MET, metformin; PIO, pioglitazone; SIT, sitagliptin. 
that industry funding was strongly associated with favourable outcomes. ${ }^{34}$ We will update our meta-analysis with further RCTs that have proper registration and less potential biases.

\section{Conclusion}

Dapagliflozin as an add-on drug to conventional antidiabetic drugs improved glycaemic control and reduced weight gain in T2DM, especially with inadequate glycaemic control by conventional drugs.

Acknowledgements The authors would like to thank Weng-hang Chan and Kai-seng Leong for their assistance in checking data for a pilot study.

Contributors YS conceived the study, developed the selection criteria, searched the literature, selected the studies, extracted the data and wrote the manuscript. YZ assisted in the study design, managed the literature, selected the studies, extracted the data, performed data analysis and wrote the manuscript. XC and WC evaluated the Cochrane risk of bias for each study. $S L$ proposed the methods, decided the study design and wrote the manuscript. All the authors read and approved the final manuscript.

Funding The work of $Y S, Y Z$, and SL was sponsored by grant 'Open systematic reviewing of clinical trials' (MYRG190-Y3-L3-ICMS11-LSW) received from the University of Macau.

Competing interests None.

Provenance and peer review Not commissioned; externally peer reviewed.

Data sharing statement No additional data are available.

Open Access This is an Open Access article distributed in accordance with the Creative Commons Attribution Non Commercial (CC BY-NC 3.0) license, which permits others to distribute, remix, adapt, build upon this work noncommercially, and license their derivative works on different terms, provided the original work is properly cited and the use is non-commercial. See: http:// creativecommons.org/licenses/by-nc/3.0/

\section{REFERENCES}

1. Ripsin $\mathrm{CM}$, Kang $\mathrm{H}$, Urban RJ. Management of blood glucose in type 2 diabetes mellitus. Am Fam Physician 2009;79:29-36.

2. Pretki M, Nolan CJ. Islet beta cell failure in type 2 diabetes. J Clin Invest 2006;116:1802-12.

3. Clar C, Gill JA, Court R, et al. Systematic review of SGLT2 receptor inhibitors in dual or triple therapy in type 2 diabetes. BMJ Open 2012;2:e001007.

4. Liebl A, Mata M, Eschwege E. Evaluation of risk factors for development of complications in type II diabetes in Europe. Diabetologia 2002;45:S23-8.

5. Saydah SH, Frafin J, Cowie CC. Poor control of risk factors for vascular disease among adults with previously diagnosed diabetes. JAMA 2004;291:335-42.

6. Dapagliflozin. http://www.nyrdtc.org/GMMMG/Groups/Publications/ GM NDE/NDE 121 Dapagliflozin.pdf

7. Chao EC, Henry RR. SGLT2 inhibition-a novel strategy for diabetes treatment. Nat Rev Drug Discov 2010;9:551-9.

8. Hu L, Zhou ZY. Research progress of sodium-glucose co-transporter-2 inhibitor drugs. Med Recapitulate 2011;12:3782-5.

9. Tahrani AA, Barnett AH. Dapagliflozin: a sodium glucose cotransporter 2 inhibitor in development for type 2 diabetes. Diabetes Ther 2010;1:45-56.

10. Freeannini E, Ramos SJ, Salsali A, et al. Dapagliflozin monotherapy in type 2 diabetic patients with inadequate glycaemic control by diet and exercise: a randomized, double-blind, placebo-controlled, phase III trial. Diabetes Care 2010;33:2217-24.

11. Musso G, Gambino R, Cassader M, et al. A novel approach to control hyperglycemia in type 2 diabetes: sodium glucose co-transport (SGLT) inhibitors: systematic review and meta-analysis of randomized trials. Ann Med 2012;44:375-93.

12. Vasilakou $D$, Karagiannis $T$, Athanasiadou $\mathrm{E}$, et al. Sodium-glucose cotransporter 2 inhibitors for type 2 diabetes: a systematic review and meta-analysis. Ann Intern Med 2013;159:262-74.
13. Zhang M, Zhang L, Wu B, et al. Dapagliflozin treatment for type 2 diabetes: a systematic review and meta-analysis of randomized controlled trials. Diabetes Metab Res Rev 2014;30:204-21.

14. Goring S, Hawkins N, Wygant G, et al. Dapagliflozin compared with other oral anti-diabetes treatments when added to metformin monotherapy: a systematic review and network meta-analysis. Diabetes Obes Metab. Published Online First: 14 November 2013. doi:10.1111/dom.12239

15. Sun YN, Zhou Y, Chen X, et al. The efficacy of dapagliflozin combined with hypoglycemic drugs in treating type 2 diabetes: protocol for meta-analysis of randomized controlled trials. Syst Rev 2013;2:103. http://www.systematicreviewsjournal.com/content/2/1/ 103 (accessed 18 Nov 2013)

16. Higgins J, Altman DG, Gotzsche PC, et al. The Cochrane collaboration's tool for assessing risk of boas in randomized trials. BMJ 2011;343:d5928.

17. Guyatt GH, Oxman AD, Vist GE, et al. GRADE: an emerging consensus on rating quality of evidence and strength of recommendations. BMJ 2008;336:924-6.

18. Duval S, Tweedie R. Trim and fill: a simple funnel-plot-based method of testing and adjusting for publication bias in meta-analysis. Biometrics 2000;56:455-63.

19. Higgins JPT, Thompson SG, Deeks JJ, et al. Measuring inconsistency in meta-analyses. BMJ 2003;327:557-60.

20. Bailey CJ, Gross JL, Pieters A, et al. Effect of dapagliflozin in patients with type 2 diabetes who have inadequate glycaemic contro with metformin: a randomised, double-blind, placebo-controlled trial. Lancet 2010;375:2223-33.

21. Bailey CJ, Gross JL, Hennicken D, et al. Dapagliflozin add-on to metformin in type 2 diabetes inadequately controlled with metformin: a randomized, double-blind, placebo-controlled 102-week trial. BMC Med 2013;11:43.

22. Bolinder J, Ljunggren Ö, Kullberg J, et al. Effects of dapagliflozin on body weight, total fat mass, and regional adipose tissue distribution in patients with type 2 diabetes mellitus with inadequate glycaemic control on metformin. J Clin Endocrinol Metab 2012:97:1020-31.

23. Bolinder J, Ljunggren Ö, Johansson L, et al. Dapagliflozin maintains glycaemic control while reducing weight and body fat mass over 2 years in patients with type 2 diabetes mellitus inadequately controlled on metformin. Diabetes Obes Metab 2014;16:159-6.

24. Henry RR, Murray AV, Marmolejo MH, et al. Dapagliflozin, metformin $\mathrm{XR}$, or both: initial pharmacotherapy for type 2 diabetes, a randomised controlled trial. Int J Clin Pract 2012;66:446-56.

25. Ljunggren Ö, Bolinder J, Johansson L, et al. Dapagliflozin has no effect on markers of bone formation and resorption or bone minera density in patients with inadequately controlled type 2 diabetes mellitus on metformin. Diabetes Obes Metab 2012;14:990-9.

26. Rosenstock J, Vico M, Wei L, et al. Effects of dapagliflozin, a sodium-glucose cotransporter-2 Inhibitor, on hemoglobin A1c, body weight, and hypoglycemia risk in patients with type 2 diabetes inadequately controlled on pioglitazone monotherapy. Diabetes Care 2012;35:1473-8.

27. Strojek K, Yoon $\mathrm{KH}$, Hruba V, et al. Effect of dapagliflozin in patients with type 2 diabetes who have inadequate glycaemic control with glimepiride: a randomized, 24-week, double-blind, placebo-controlled trial. Diabetes Obes Metab 2011;13:928-38.

28. Wilding JP, Norwood P, Tjoen C, et al. A study of dapagliflozin in patients with type 2 diabetes receiving high doses of insulin plus insulin sensitizers: applicability of a novel insulin-independent treatment. Diabetes Care 2009;32:1656-62.

29. Wilding JP, Woo V, Soler NG, et al. Long-term efficacy of dapagliflozin in patients with type 2 diabetes mellitus receiving high doses of insulin a randomized trial. Ann Intern Med 2012;156:405-15.

30. Wilding JP, Woo V, Soler NG, et al. Dapagliflozin in patients with type 2 diabetes receiving high doses of insulin: efficacy and safety over 2 years. Diabetes Obes Metab 2014;16:124-36.

31. Jabbour SA, Hardy E, Sugg J, et al. Dapagliflozin is effective as add-on therapy to sitagliptin with or without metformin: a 24-week, multicenter, randomized, double-blind, placebo-controlled study. Diabetes Care 2014;37:740-50.

32. U.S. Food and Drug Administration. FDA Briefing Document. NDA 202293. Dapagliflozin tablets, 5 and $10 \mathrm{mg}$. Rockville, MD: US Food and Drug Administration, 2011.

33. Little RJ, D'Agostino R, Cohen ML, et al. The prevention and treatment of missing data in clinical trials. N Engl J Med2012;367:1355-60.

34. Khan SN, Mermer MJ, Myers E, et al. The roles of funding source, clinical trial outcome, and quality of reporting in orthopedic surgery literature. Am J Orthop (Belle Mead NJ) 2008

37:E205-12 